(Mini Review ARticle)

\title{
Enzyme secretion in Staphylococcus aureus strains
}

\author{
Pochkhua Khatuna ${ }^{1}$ and Khetsuriani Shorena ${ }^{2, *}$ \\ ${ }^{1}$ St. Andrew the First-Called Georgian University of the Patriarchate of Georgia. \\ ${ }^{2}$ Tbilisi State Medical University, Georgia.
}

Publication history: Received on 03 May 2020; revised on 13 May 2020; accepted on 14 May 2020

Article DOI: https://doi.org/10.30574/wjarr.2020.6.2.0142

\begin{abstract}
Staphylococcus aureus manifests many enzymes, which are correlated with the virulence of bacteria. The aim of the study was to determine enzymes secretion in Staphylococcus aureus strains. The results of the study showed that some enzymes which involve in virulence (plasma coagulase, catalase, urease, protease, and lecithinase, hemolysins) were secreted frequently in multidrug resistant and methicillin resistant $S$. aureus strains.
\end{abstract}

Keywords: Staphylococcus aureus; Virulence; Enzymes; Multidrug resistance

\section{Introduction}

Infectious diseases remain one of the leading causes of death worldwide. Natural genetic variations, recombinations, and adaptations allow new strains of known pathogens to appear [1]. Bacterial multidrug-resistance causes a substantial health burden [2].

Although Staphylococcus aureus is primarily a commensal microbe, it has the potential to cause a wide range of diseases that can vary considerably in severity [3]. S. aureus is the most isolated human bacterial pathogen and an important cause of infections of endovascular infections, skin and soft tissues, septic arthritis, sepsis, pneumonia, osteomyelitis, foreign body infections and endocarditis [4]. S. aureus is a common cause of infections in patients in intensive care units, and in many countries, it is often resistant to methicillin (MRSA strains)

S. aureus is one of the most common causes of clinical infections worldwide and has attracted significant public attention due to the increased mortality associated with multidrug resistance [5,6]. Currently, S. aureus is the main common cause of nosocomial infections, and as an increasing number of patients receive treatment outside the hospital, this is an increasing public concern [7].

In addition to the toxins, $S$. aureus produces a large number of virulence factors that have enzymatic properties enzymes for degradation of tissue components. Secreted enzymes (exoenzymes) function to break down bacterial and host molecules for nutrient acquisition, bacterial survival, and dissemination [8].

Based on the foregoing, the aim of the present study was to identify the pathogenicity factors of S. aureus - enzymes and carbohydrates and to check their activity in multiresistant (MDRSA) and MRSA strains.

The study included clinical isolates identified by appropriate methods $[9,10]$. Media and reagents provided by these methods were used. In particular, the study was carried out taking into account morphological, tincture, cultural and biochemical features. Two methods were used to study antibiotic resistance: disk diffuse [11] and a Vomek2 analyzer (Biomerieux). S. aureus strains were divided into 2 groups: resistant to MDRSA (group I) and MRSA (group II). We studied the presence of some enzymes which are involved in the pathogenicity of bacterium.

\footnotetext{
${ }^{*}$ Corresponding author: Khetsuriani Shorena
} 
The test results are given in the table N1.

Table 1 Enzymes of $S$. aureus

\begin{tabular}{lllll}
\hline \multirow{2}{*}{ Identity markers } & \multicolumn{2}{c}{ Group I } & $\mathbf{n = 5 0}$ & \multicolumn{2}{c}{ group II } & $\mathbf{n}=\mathbf{5 0}$ \\
\cline { 2 - 5 } & $\mathbf{a b s}$ & $\mathbf{\%}$ & abs & $\mathbf{\%}$ \\
\hline Urease-positive & 39 & $78,0 \pm 5,85$ & 48 & $96,0 \pm 2,77$ \\
Hemolytic activity (positive) & 50 & 100 & 50 & 100 \\
Proteolytic activity & 43 & $86,0 \pm 4,90$ & 47 & $94,0 \pm 3,35$ \\
Plasmocoagulase-positive & 43 & $86,0 \pm 4,90$ & 50 & 100 \\
Catalase-positive & 50 & 100 & 50 & 100 \\
Lecitinase activity & 41 & $82,0 \pm 5,43$ & 48 & $96,0 \pm 2,77$ \\
\hline
\end{tabular}

As can be seen from the table, catalase and hemolytic activity is the same for all groups and is equal is $100 \%$. Lecithinase activity and proteolytic production were detected in $82 \pm 5.43 \%$ and $86,0 \pm 4,90 \%$ (group I) and $96 \pm 2.77 \%$ and $94,0 \pm 3,35 \%$ (group II), respectively. Urease activity is less in group I $(78,0 \pm 5,85 \%)$ than in group II $(96,0 \pm 2,77 \%)$, Strains from both groups revealed high enzyme activity which was the highest in MRSA strains.

\section{Conclusion}

MDRSA and MRSA strains are characterized with high enzyme secretion frequency. Enzymes which determine virulence in these strains - catalase, urease, plasma coagulase, protease, lecithinase and hemolysins were highly active. These enzymes are involved in the pathogenesis of $S$. aureus infections.

\section{Compliance with ethical standards}

\section{Disclosure of conflict of interest}

Authors of the manuscript have no conflict of interests to disclose.

\section{References}

[1] Kaszanyitsky EJ, Janosi S, Egyed Z, Agost G and Semjen G. (2003). Antibiotic resistance of staphylococci from humans, food and different animal species according to data of the Hungarian resistance monitoring system in 2001. Acxta Vet. Hung, 51(4), 451-64.

[2] Jernigan JA, Hatfield KM, et al. (2020). Multidrug-Resistant Bacterial Infections in U.S. Hospitalized Patients, 2012-2017. N Engl J Med., 382(14), 1309-1319.

[3] Jenul C and Horswill AR. (2018). Regulation of Staphylococcus aureus virulence. Microbiol Spectr. 6(1).

[4] Mc callumn N, Berger-Bachi B and Senn M. (2010). Regulation of antibiotic resistance in Staphyloccus aureus. Int. J. of Med. Microb, 300(2-3), 118- 129.

[5] Mc Murray LW, Kernodle DS and Barg NL. (1990). Characterisation of widespread strains of methicillin susceptible Staphylococcus aureus associated with nosocomial infections J. Infect. Dis, 162, 759-762.

[6] Barua S, Joshi A Sh and Swaminathan R. (2017). Prevalence of Multidrug Resistant Staphylococcus aureus and its Antimicrobial Susceptibility Pattern in a Tertiary Care Hospital in Navi Mumbai, India. Int. J. Curr. Microbiol. App. Sci, 6(3), 370-375.

[7] Lowy FD. (1998). Staphylococcus aureus infections. N. Engl. J. Med., 339, 520-532.

[8] Tam K and Torres VJ. (2019). Staphylococcus aureus Secreted Toxins \& Extracellular Enzymes Microbiol Spectr. $7(2)$.

[9] Baron EJ, Peterson LR and Finegold SM. (1999). Diagnostic Microbiology 9th edition Mosby, 320-345. 
Pochkhua and Khetsuriani / World Journal of Advanced Research and Reviews, 2020, 06(02), 110-112

[10] Bergey's Manual of Determinative Bacteriology John G. Holt Lippincott Williams \& Wilkins, 1994 -787.

[11] Clinical and Laboratory Standards Institute. (2006). Performance standards for antimicrobial disk susceptibility tests. Approved standard. $9^{\text {th }}$ ed. (M2-A9). Wayne, PA: Clinical and Laboratory Standards Institute.

\section{How to cite this article}

Pochkhua K and Khetsuriani S. (2020). Enzyme secretion in Staphylococcus aureus strains. World Journal of Advanced Research and Reviews, 6(2), 110-112. 